\title{
La violència física i econòmica contra les dones a la Mallorca del segle XVII: una aproximació
}

\section{Physical and economic violence againt women in the Mallorca of the XVII century: an approach}

\author{
ViCTÒRIA BAUÇÀ NiCOLAU \\ victoria.b8.95@gmail.com
}

Universitat de les Illes Balears

\begin{abstract}
Resum: En aquesta primera aproximació a la Mallorca del segle XVII, es pot veure com les dones patien diferents tipus de violència. Per una banda, la física, que era exercida tant per part de desconeguts com per part dels marits dins de l'entorn conjugal. La fugida de la maltractada era la solució més habitual i, en moltes ocasions, la disputa acaba amb divorci. per altra banda, s'ha documentat l'existència d'una violència que es pot denominar econòmica i que es basa en l'exclusió de la dona de les seves pròpies possessions, cosa que conduïa a llargs litigis per a la restitució dotal o per a reclamar una herència. Generalment, aquesta violència es donava quan les dones quedaven soles i en situació de vulnerabilitat econòmica i social, i era exercida, de manera habitual, per homes propers a elles de diferents modes. Així i tot, es comprova el tarannà reivindicatiu i actiu de les dones mallorquines davant aquests tipus de violències.
\end{abstract}

Paraules clau: violència, maltractament, dona, dot, herència

Abstract: In this first approach to Mallorca in the seventeenth century, we can see how women suffered different types of violence. On the one hand, the physical violence was exercised both by strangers and by husbands within the conjugal environment. The most common solution to this violence was the escape of the woman who was being abused. In many cases, the dispute ended in divorce. On the other hand, we documented the existence of violence that can be called economic. This type of violence is based on the exclusion of women from their own possessions, which led to lengthy litigation for dowry restitution or to claim an inheritance. Generally, this violence occurred when women were left alone and in a situation of economic and social vulnerability. The economic violence was usually exercised by men close to the victims in different ways. However, we can highlight the vindictive and active disposition of Mallorcan women in the face of these types of violences.

Keywords: violence, maltreatment, woman, dowry, inheritance

\footnotetext{
* Aquest treball forma part del projecte PRD 2018-17 titulat "Conflicte i identitat en el Regne de Mallorca (Segles XIV-XVIII)" i finançat per la Comunitat Autònoma de les Illes Balears a través de la Direcció General de Política Universitària i Recerca amb fons procedents de la Llei de l’impost sobre estades turístiques (ITS 2017-06).
}

DATA PRESENTACIÓ: 11/09/2020 ACCEPTACIÓ: 21/09/2020 • PUBLICACIÓ: 10/12/2020 
Victòria Bauçà Nicolau. La violència física i econòmica contra les dones a la Mallorca del segle

XVII: una aproximació

\section{Introducció}

Durant el segle XVII, en el Regne de Mallorca van existir diferents violències en contra de les dones. A partir de l'anàlisi de diferents casos particulars i seguint la perspectiva de gènere, es pot constatar com el tracte i les relacions entre homes i dones eren complexos i es fonamentaven en la subordinació de la dona respecte de l'home. Aquesta desigualtat implicava, en ocasions, l'ús de la violència per part de l'home com a forma de correcció o disciplina, socialment acceptada, per a garantir l'obediència femenina (Mantecón 2009: 223).

La subordinació de la dona respecte a l'autoritat de l'home no ve de nou en el context de l'edat moderna, quan la figura del pater familias, en paral lel que l'Estat, s'enforteix (Lorenzo 1989: 120 i López-Cordón 1998: 110). La família com a institució primera de la nova configuració social, política i religiosa resulta ser la base per entendre l'esdevenir del segle XVII.

Malgrat que en parlar de violència i de gènere, encara avui i desgraciadament, ens ve a la ment el maltractament de dones per part dels seus marits, al segle XVII existien altres violències vers les dones. Aquest plantejament no nega l'existència de la violència física en la societat moderna, sinó que aquesta no era l'única.

Per a localitzar la violència que patien les dones al segle XVII al Regne de Mallorca s'ha consultat documentació de la Reial Audiència, tant de la cúria criminal com de la cúria civil, així com també de la part juridicoadministrativa, com són els Presidals decrets. ${ }^{1}$ Per a aquesta primera aproximació les fonts primàries a les quals s'ha acudit han estat, per tant, de l'àmbit judicial.

La primera pista per a rastrejar la violència la trobem en els Presidals decrets. Aquesta documentació és important a l'hora d'estudiar la dona en el segle XVII al Regne de Mallorca, ja que la seva presència és constant i la informació que ofereix, abundant (Bauçà 2020: 261-264). En els casos estudiats que fan referència a violència contra la dona s'aporta una valuosa informació tant dels protagonistes i la seva història com dels processos que tenen oberts en matèria judicial i eclesiàstica. Una de les raons del seu ús per a aquest estudi és que a través d'aquest tipus de documents les demandants obtenien els ingressos per a continuar els plets o els diners per a mantenir-se de manera que havien d'al legar i justificar la seva situació.

Aquest tipus de documentació juridicoadministrativa ofereix valuosos testimonis de dones que van patir en primera persona la violència pel simple fet de ser dones. Les fonts permeten posar en context la seva situació, entendre el perquè de les seves actuacions i les seves reaccions, a banda de poder constatar el paper de la justícia respecte aquest tipus d'agressions.

1 Els Presidals decrets són un grup documental sorgit a finals del segle XVI, propi de la Reial Audiència de Mallorca, qualificat com a font d’administració reial, ja que la seva funció no només era jurídica. Són peticions de la població al virrei per a cobrar deutes, satisfer interessos, aclarir disputes testamentàries, herències i fideïcomisos, així com també reclamar diners per a subsistir i/o litigar. (Planas 2010: 28-29 i Juan 1994: 62-63) 
Victòria Bauçà Nicolau. La violència física i econòmica contra les dones a la Mallorca del segle XVII: una aproximació

Les peticions «colaterals» per a sustentar-se per haver-se separat o les demandes de restitució de dots i herències, per exemple, ens serveixen per a prendre un primer punt de contacte amb la realitat de la violència física i econòmica que patien les dones del segle XVII a Mallorca. A la vegada, ens donen suficient informació per a cercar les persones implicades en els plets i/o sentències civils de la Reial Audiència i de la cúria eclesiàstica. ${ }^{2}$

En parlar de violència fora de l'àmbit familiar és suficient acudir a la documentació judicial, però quan es produeix dins d'aquest context s'ha de consultar també l'eclesiàstica, ja que és on es registraven les peticions de divorci (Planas 2000: 54). La cúria eclesiàstica era l'encarregada d'aquests processos que venien motivats, en moltes ocasions, per la violència exercida per part del marit cap a la seva esposa (Espín 2016: 171).

Totes aquestes fonts són útils per poder veure quines institucions van implicar-se per a salvaguardar la situació de les dones, així com també es poden comprovar les reaccions de l'entorn més immediat de la víctima i de l'agressor, i no només en termes de violència física. Amb aquesta informació podem traçar un mapa d'actuacions per a entendre la consideració social de la violència en contra de la dona en el segle XVII al Regne de Mallorca i quines solucions podia tenir.

\section{La violència física contra les dones}

La violència física contra les dones ha estat objecte d'estudi de nombrosos treballs d'un temps ençà; per començar, basta destacar el treball de A. Gil (2008). La violència va donar-se arreu dels territoris europeus al llarg dels segles de la modernitat. Estudis com els de R. Muchembled i Natalie Z. Davis per a França i de Lawrence Stone -i altres- per al món anglosaxó corroboren aquests conflictes (De la Pascua 2002: 78-84). En diferents ocasions, però s'ha matisat que a nivell moral i social estava acceptat l'ús de la violència del marit envers la seva esposa com a forma de correcció o bé per a garantir la seva obediència, cosa que es traduïa en el reforçament de la seva autoritat.

El que ens hem de plantejar en enfrontar un estudi d'aquestes característiques és si estava permès tot tipus de violència $\mathrm{o}$, si bé, només era l'abús el que era contestat, com s'ha vist en altres llocs. De la mateixa manera que ens hem de qüestionar si aquesta violència exercida contra les dones només es restringia a l'àmbit familiar o marital. Resulta clar que les dones rebien violència des de diferents àmbits i de diferents formes; no era un fet aillat.

Per una banda, la documentació ha permès constatar que les dones estaven exposades a la violència de fora de l'entorn domèstic. En un medi majoritàriament rural, com el mallorquí, i en ple segle de les disputes entre bandejats, les dones -especialment les que estaven soles- es trobaven en una situació de vulnerabilitat. Les distàncies relativament petites entre viles i la coneixença de la majoria de la població que hi vivia resultava un factor clau a l'hora d'identificar les persones que podien cometre accions criminals.

2 Tota la documentació consultada està localitzada a l'Arxiu del Regne de Mallorca, d'ara endavant ARM. 
Victòria Bauçà Nicolau. La violència física i econòmica contra les dones a la Mallorca del segle XVII: una aproximació

En aquest sentit, crida l'atenció el cas de Joana Maria Arbona, viuda de Joan Arbona. ${ }^{3}$ Denuncià que una nit havien anat a casa seva tres homes: Pere Francesc Vicens, Damià Vicens i Bartomeu Fontanet, tots tres bandejats de les viles de Fornalutx i Sóller. ${ }^{4}$ Aquests es presentaren a les tres de la matinada i començaren a pegar cops a la porta i, sota amenaces de tomar-la, van fer que la viuda obrís. Els tres bandejats en cercaven un quart, suposadament del bàndol contrari sota la sospita de ser amic del fill de Joana Maria. Un cop reconeguda la casa i haver comprovat que no hi era la persona que cercaven, Pere Francesc Vicens, va colpejar a Joana Maria amb la carabina que portava, ja que tots tres anaven armats.

Joana Maria Arbona va tardar tres mesos a denunciar la feta, ja que, aconsellada pel Batle de Sóller, ho havia de deixar passar. Però en assabentar-se que els Vicens volien acusar el seu fill d'anar amb el bandejat que cercaven va decidir denunciar. De manera franca va assumir que no tenia més testimonis que els seus tres fills, que eren amb ella en el moment de l'atac. El major, Joan Arbona de vint anys, en sentir els cops a les portes i en veure entrar els bandejats a casa seva va fugir per la teulada; la petita, Margalida, de nou anys, va anar a casa d'una veïnada i la mitjana, de 10 anys, va quedar amb la seva mare. Tots tres, però, reafirmaren la història explicada per Joana Maria.

Independentment del relat, cal fixar-se que després d'haver escorcollat la casa i haver comprovat que allò que els bandejats cercaven no hi era, encara van colpejar a Joana Maria Arbona. La viuda havia complit amb les ordres que li havien donat i permeté que reconegueren la seva casa sota les amenaces d'espenyar-li les portes. Així i tot, va acabar rebent els cops d'un dels bandejats. Per què? Si no hi havia el que cercaven, què motivà a Pere Francesc Vicens a colpejar la viuda? Si el seu fill hagués sortit a defensar-la, també haurien pegat a la seva mare? Si hagués estat un home qui hagués obert, hauria acabat igual?

Són preguntes que s'han de deixar sense resposta, encara que si tenim en compte el clima de violència que es vivia en el segle XVII a Mallorca i la pròpia que patien les dones, fa pensar que era un fet estructural. La vulnerabilitat de trobar una dona sola servia d'excusa per a escometre contra ella sense cap altra justificació. Probablement, si hagués estat un home qui hagués obert ens trobaríem davant un cas diferent i no amb una denúncia a la cúria criminal.

Per altra banda, la violència física contra les dones també era present en l'entorn domèstic, ja que, molt sovint apareix documentació en la qual la dona es presenta com a maltractada pel seu marit. Aquest maltractament resulta un fet estructural que respon al que anteriorment s'ha esmentat: el reforçament de l'autoritat de l'home per assegurar la subordinació i obediència de la dona. No es podia acceptar cap tipus de qüestió del seu poder sobre la família i, molt manco, sobre la seva esposa, qui, per la seva pròpia naturalesa era considerada inferior.

3 ARM AA 935/7 3/59

4 A Damià Vicens el trobam demanant la gràcia reial per al seu alliberament de la presó a canvi de treballar en aquest mateix lloc poc després de 1667. ARM AA 1023

SCRIPTA, Revista internacional de literatura i cultura medieval i moderna, núm. 16 / desembre 2020 / pp. 343-365 ISSN: 2340-4841 · doi:10.7203/SCRIPTA.16.19234 
A la vegada, s'ha de tenir present que el matrimoni no era de lliure elecció: es tractava d'un contracte signat entre famílies, on els pares de les núvies elegien els millors candidats a nivell econòmic. Per la qual cosa la lliure elecció i molt manco l'amor no hi tenien cabuda -sentiment que tampoc no assegurava un matrimoni feliç. Prova d'aquesta imposició és l'existència habitual del matrimoni clandestí, l'adulteri i la bigàmia (Ortega 1997: 267-271).

Aquestes tres formes de relació extramatrimonial eren regulades per les Franqueses i Privilegis del Regne de Mallorca, així com també pels successius edictes dels lloctinents de Mallorca. Planas (2000) ens parla d'aquests i altres delictes contra el matrimoni i la moral sexual, entre els quals no s'hi trobava la violència en contra de l'esposa. Tanmateix allò que es penava era l'atac a l'honestedat de la dona i de la família, i no a la llibertat de la dona. Un clar exemple és un dels càstigs imposats als homes que havien violat a dones solteres, que no era d'altre que casar-se amb la víctima.

A l'edat moderna es produïa una profunda identificació entre pecat i delicte, per la qual cosa no és estrany que certes conductes estiguessin legislades per la justícia no eclesiàstica. A banda que alguns d'aquests delictes estiguessin regulats per les lleis primeres del Regne, la majoria es regien pels Usatges de Barcelona, els Furs de València i els diferents edictes que anaven promulgant els successius lloctinents de Mallorca al llarg dels seus mandats (Planas 2000).

Ja en el segle XIV el matrimoni clandestí es condemnava amb penes de flagel lació i exili i en el XV es penava amb la mort al nuvi si la núvia era menor de vint-i-cinc anys, mentre ella era declarada ingrata i desheretada (Quadrado 2002: 75, 87). S’ha de tenir en compte que el dret mallorquí exigia el consentiment dels pares o tutors de les menors que es casaven. En el cas que el matrimoni es produís clandestinament les donzelles perdien els béns i els drets hereditaris. Gràcies a les noves disposicions de Trento aquest tipus de trencament de la llei va ser molt més fàcil de detectar (Planas 2000: 50).

La bigàmia i l'adulteri van ser acceptats en el principi de la creació del Regne de Mallorca pel fet de constituir un territori de conquesta i colonització fins a la primera meitat del segle XIV. Malgrat aquesta primera tolerància, amb el temps van passar a ser objecte d'una major regulació que penava a homes i dones que havien atemptat contra el matrimoni (Planas 2000: 45-51). Llavors, les persones que haguessin incorregut en el delicte de bigàmia havien de ser executats i la seva llengua clavada a una taula. En el cas de no haver consumat el matrimoni, el bígam o la bígama havia de ser desterrat o desterrada (Quadrado 2002: 87, 204).

Aquests delictes i altres circumstàncies podien conduir a la disputa entre els cònjuges i, per tant, la violència marital feia acte de presència. No sempre tenia les mateixes motivacions, però era un fenomen habitual (De la Pascua 2002: 81-84). Aquest tipus de violència ha estat focus d'atenció d'estudis a diferents llocs de la península. Destaquen, entre altres, els referits al País Basc per part d’I. Reguera (2013) i A. Aragón (2011); els de Madrid de Margarita Ortega (2006); els treballs sobre Castella de P. L. Lorenzo (1989) i R. S. Espín (2016); els de T. M. Mantecón per a Cantàbria (1997), etc. 
A Mallorca, la Carta de Franqueses i els Privilegis només legislaven el matrimoni clandestí, la bigàmia i l'adulteri, com s'ha referit anteriorment. Tampoc en la resta d'edictes es fa referència a la permissivitat d'exercir violència sobre la dona. Una altra cosa és que socialment tingués una consideració millor o pitjor. Així i tot, en molts llocs es constata que la violència del marit contra l'esposa estava acceptada, sempre que fos moderada (Morte 2012: 214 i Garibeh 2019: 349).

En ser un concepte tan lligat a l'actualitat és inevitable sentir la necessitat d'entendre les arrels d'aquesta violència o de comprovar si les nostres avantpassades ja van haver de passar per situacions del que avui diem violència de gènere o domèstica. Així, cercant entre els documents del segle XVII es troben casos que demostren que aquesta violència existia i no de manera aillada.

Com a exemple es presenten dos casos localitzats a la documentació de la Reial Audiència de Mallorca. El primer cas és el de Jerònima Perelló Ector, qui es presentava com a maltractada davant les autoritats per part del seu marit, el paraire Nadal Perelló. ${ }^{5}$ Denunciava que Perelló l'havia maltractada fins a voler matar-la i per evitar que fugís li va prendre tota la seva roba. Finalment, ella va poder refugiar-se a la casa de la Pietat. ${ }^{6}$ Jerònima expressà la seva intenció de quedar en aquesta institució fins que sortís la resolució a la petició de divorci que havia fet.

Quan feia nou mesos que es trobava a la Pietat va demanar a les autoritats competents que dictessin que el seu marit li retornés la seva roba i se li taxessin aliments per a poder mantenir-se. ${ }^{7}$ Per a reforçar el seu relat oferí el testimoni de la Priora de la Pietat. Finalment, per Presidal decret del 7 d'octubre de 1614 se li taxaren 16 sous a l'any, ${ }^{8}$ a pagar per Nadal Perelló, mentre ella romangués a la Pietat, és a dir, fins que sortís la resolució del procés de divorci.

En segon lloc, trobem una petició feta per Gabriel Casador, pare d'Esperança Casador. ${ }^{9}$ Aquesta s'havia casat el 1607 amb Nicolau Pou, cirurgià de Ciutat. El pare havia constituit en dot 400 lliures per al matrimoni, a pagar de diferents maneres. Però la seva filla era maltractada pel dit Pou, fins al punt que va haver de refugiar-se a casa del seu pare. Davant aquesta situació va iniciar el procés per a obtenir el divorci, però així i tot, davant les promeses de canvi del cirurgià va decidir tornar a casa i donar-li una nova oportunitat. Aquesta decisió va resultar ser un error, ja que novament va ser maltractada.

\footnotetext{
5 ARM, AA 64, f. 178r, 178v

6 La casa de la Pietat era una institució encarregada de recollir dones procedents de la prostitució, on entraven de manera voluntària. Es tractava d'un centre de reclusió regentat per monges que pretenia redirigir a les dones que hi acudien cap a una vida més honesta. (Planas 1999: 93).

7 Entenem «aliments» segons la definició donada pel Diccionari Català-Valencià-Balear: «en jurisprudència, entrega pecuniària per a la manutenció y subsistència d'algú».
}

8 Les quantitats que apareixen en tot el document estan en moneda de Mallorca: lliures, sous i diners.

9 ARM AA 64, ff. 430r-430v/434r-437r

SCRIPTA, Revista internacional de literatura i cultura medieval i moderna, núm. 16 / desembre 2020 / pp. 343-365 ISSN: 2340-4841 · doi:10.7203/SCRIPTA.16.19234 
Quan ja feia sis mesos que es trobava, un altre cop, refugiada a casa del seu pare demanava en el procés que se li concedís el divorci i la restitució del seu dot, més interessos. Mentrestant, el seu pare reclamava que se li paguessin els costos del litigi i es taxessin aliments per a la seva filla mentre visqués a casa seva, ja que els diners que ell havia destinat per a ella els havia constituït en dot.

Per a fonamentar aquesta declaració i demostrar la veracitat dels fets, a la vegada que justificar tals peticions, es van aportar tres testimonis. El primer, un escriba de la cúria eclesiàstica, i el segon, el doctor teòleg de Santa Eulàlia, declararen que Esperança Casador havia aportat raons per a deixar de conviure amb el seu marit i que es trobava a casa del seu pare. També que havia iniciat el procés de divorci per intentar canviar l'actitud del seu marit, cosa que no va ser possible perquè en tornar a casa va ser novament maltractada. A més, van afirmar que el cirurgià l'amenaçava amb pegar-li i no restituir-li el dot perquè no tornés a casa del seu pare, cosa que tanmateix va fer i va demanar el divorci.

Finalment, el tercer testimoni, Sebastià Guasp, declarava haver presenciat el maltractament a Esperança en primera persona, quan es trobava a casa del matrimoni. Va veure com Nicolau Pou tirava a la seva esposa al terra, la feia despullar i li pegava. Sebastià acudí a la seva ajuda i la trobà ajupida en terra. El jove apuntava a la seva declaració haver trobat a Esperança «molt maltractada» $\mathrm{i}$ definia a Nicolau Pou com a «home de molt terrible condició» i «de condició desbaratada». A més, apuntava com el mateix vespre la gent del veïnat s'adonà que Nicolau Pou tornava a maltractar la seva esposa i va ser quan es va veure forçada a tornar a casa del seu pare. Per Presidal decret del 23 de desembre de 1616 es taxaven 45 lliures per a Esperança Casador, a pagar pel seu marit, Nicolau Pou, durant el temps que duràs el procés de divorci.

En els dos exemples es presenten testimonis per a corroborar la seva condició de dones maltractades, a banda del seu propi relat. D'aquesta manera les autoritats podien comprovar la veracitat de la història d'aquestes dones. Tant en un cas com a l'altre observem la implicació de l'estament eclesiàstic: la priora de la Pietat en el primer cas i el doctor teòleg de Santa Eulàlia en el segon. Des del moment en què Trento instituí el matrimoni com a sagrament és inevitable no veure la implicació eclesiàstica en aquest tipus de casos, ja que el vincle religiós que havien contret home i dona no es podia dissoldre.

A més a més, la totalitat dels testimonis i la implicació del mateix pare d'una d'elles en la demanda presidal ens permet constatar la importància del suport i la implicació de l'entorn de la víctima per a poder sobreviure a la violència. L'ajuda que poguessin rebre les dones maltractades podia ser vital, mai millor dit, ja que podia suposar evitar el seu assassinat. Tant els veïnats com la família, servien de salvavides d'aquestes dones que fugien d'un matrimoni infeliç i dolorós.

La dona maltractada era considerada moralment com a culpable. Aquesta consideració procedia de la literatura moral i la concepció eclesiàstica de la inferioritat femenina que havia d'obeir i acceptar resignadament el tarannà violent del seu espòs, la qual cosa garantia la conservació de l'estructura 
Victòria Bauçà Nicolau. La violència física i econòmica contra les dones a la Mallorca del segle XVII: una aproximació

de poder a favor de l'home (De la Pascua 2002: 89 i Morte 2012: 214-215). Si la dona pretenia sortir d'aquesta situació, es trobava amb més violència, vexacions, amenaces de mort i de perdre el dot, com es pot comprovar en el casos exposats (Reguera 2013: 160 i Garibeh 2019: 352). A més a més, el propi sentiment de culpabilitat i d'anar en contra de la decisió paterna, que havia pactat tal matrimoni, evitava la denúncia per part de la dona (Espín 2016: 190 i Morte 2012: 214-215).

Davant aquesta situació es troben diferents reaccions: en primer lloc, la justícia intentava implicarse el manco possible en les disputes marit-esposa per considerar que pertanyien a l'àmbit privat (Lorenzo 1989: 121 i De la Pascua 2002: 85). En segon lloc, la família i, més concretament el pare, podia reaccionar de dues maneres: o bé amb passivitat per tal de conservar l'estatus econòmic $\mathrm{i}$ social o bé oferir refugi i suport a la seva filla, com passa també amb Esperança Casador, per sentirse el causant per haver estat ell qui havia pactat el matrimoni (Morte 2012: 213).

Finalment, els veïnats i veïnades podien reaccionar igual que la família, però, en general, solien actuar en favor de la víctima, ja fos donant suport o bé servint de testimonis en els mateixos judicis (Morte 2012: 217 i Reguera 2013: 156-157). En moltes ocasions el rebuig a la violència marital i la intervenció dels veïns i familiars va conduir a la denúncia per part de la dona maltractada, qui se sentia amb suport suficient per emprendre una demanda d'aquest tipus: si no tenien aquest suport no denunciaven (Morte 2012: 214-215 i López-Cordón 1998: 126). Aquesta ajuda també suposava evitar un final tràgic, encara que no era infal lible (Mantecón 2013: 103).

Ambdós casos presentats mostren una resposta idèntica per part de la dona maltractada: la fugida de la casa familiar i la petició de divorci a les autoritats corresponents. Escapar de les mans dels seus marits era l'única manera de deixar de patir la seva violència i era una de les opcions que justificava la petició de divorci. De fet, la fugida era sinònim de separació del matrimoni a nivell pràctic (De la Pascua 2002: 95).

Per tant, la sortida més efectiva que tenia la dona maltractada era fugir de casa seva i cercar un lloc on poder recuperar-se dels cops i poder reflexionar sobre quin era el destí que havia d'emprendre. Malgrat que l'opció recomanada jurídicament era retornar al costat del marit -com va fer en un principi Esperança-, aquests tipus de situacions no solien millorar. Per això, es podia recórrer a la petició del divorci, cosa que estava en mans de l'autoritat eclesiàstica.

No podem entendre el divorci en la manera actual, sinó que es referia a la sentència per la qual es deixava d'habitar conjuntament de manera definitiva o temporal (Espín 2016: 168). És a dir, era una separació del matrimoni de iure, encara que de facto s'havia produit en el mateix moment de la fugida de la dona de la casa marital. Mentre que s'estava pendent de la sentència, la dona havia de ser mantinguda pel marit agressor, cosa que es pot comprovar en el cas de Jerònima, i havia de retornar-li els seus béns: dot, escreix i béns parafernals (Espín 2016: 173, 188; López-Cordón 1998: 126 i Reguera 2013: 144). 
Victòria Bauçà Nicolau. La violència física i econòmica contra les dones a la Mallorca del segle XVII: una aproximació

La solució per la qual el matrimoni passava a viure en cases separades i la mateixa petició de divorci serveix per a qüestionar la premissa d'una violència conjugal «acceptada» per la societat del moment. Constantment es pren com a argument haver estat «molt maltractada» per demanar la separació, i així no haver de retornar i resignar-se a patir els cops del marit. Per la qual cosa s'entén que aquesta violència era raó suficient per a la justícia.

Aquesta era una solució habitual en tots els territoris durant l'edat moderna, com esmenten Ana Morte (2012: 220) i Antuanett Garibeh (2019: 350). La fugida i la consegüent demanda de divorci eren processos que solien allargar-se (Morte 2012: 218). Per això, s'ha de destacar la importància del que es coneix com «infrajustícia», és a dir, aquells pactes i acords que es prenien fora de les institucions judicials (De la Pascua 2002:84), o bé davant notaris, com les cartes notarials de perdó (Garibeh 2019: 353-357).

La justícia, tant eclesiàstica com civil, apostava pel retorn a la cohabitació d'aquells que s'havien separat i és que Trento introduí que el divorci només havia de donar-se en causes justificades, les quals eren escasses (Espín 2016: 170-171). En estar majoritàriament acceptada la violència contra la dona, allò que interessava era el manteniment de l'ordre social sustentat en el matrimoni i en la família, per la qual cosa sempre que era possible s'intentava que el procés de divorci no culminés, sinó que els implicats es reconciliessin (Espín 2016: 176, 189). De fet, a Mallorca es troben diferents edictes que exhorten al retorn a la cohabitació en breus períodes de temps, cosa que ens indica que aquests no devien complir-se i que les separacions eren freqüents (Planas 2000: 54).

En nombrosos treballs que estudien aquest mateix tema a la península Ibèrica estableixen que la violència contra les dones estava socialment i moralment acceptada i allò que es penalitzava era l'abús. Els moralistes eren els que havien fixat la imatge negativa de la dona per la qual cosa qualsevol desviació de la seva conducta podia ser castigada amb violència. De fet, era considerada un dret de correcció i una manera de garantir l'obediència (De la Pascua 2002: 82).

La justificació es basava en els mateixos discursos imperants a l'edat moderna, que fins i tot tenien el seu reflex en el teatre de l'època (Lorenzo 1989: 122 i Petro del Barrio, 2006), i en assegurar el codi d'honor (De la Pascua 2002: 87). Tots els autors, però coincideixen en establir que només era acceptat un cert nivell de violència o una violència moderada (Morte 2012: 214, Garibeh 2019: 349, Lorenzo 1989: 123 i López-Cordón 1998: 109, 125).

La concepció de la violència permesa i de l'abús estava sustentada en les paraules dels moralistes i teòlegs, però què era abús de violència i qui en fixava els límits? Fins quin punt s'havia d'acceptar? Són preguntes de difícil resposta però sembla que la reiteració d'aquesta conducta i la proximitat a la mort de la víctima eren els criteris més comuns per a parlar d'abús de violència en un matrimoni.

A la vegada s'ha de posar l'atenció sobre el tractament que rep el marit com a agressor, ja que, per exemple, en el segon cas presentat, a Nicolau Pou se'l tractava d'home de «condició terrible i desbaratada». La majoria de treballs coincideixen en traçar un perfil de marit agressor que sol tenir 
Victòria Bauçà Nicolau. La violència física i econòmica contra les dones a la Mallorca del segle XVII: una aproximació

com a característiques ser un home gandul, begut i reincident (Reguera 2013: 168-169). Altres vegades es presenta un marit gelós, consentidor o enfastidit d'un matrimoni imposat (Mantecón 2013: 88).

En els casos anteriors no sembla que els marits (Nadal Perelló i Nicolau Pou) encaixin en aquests perfils, sinó que en ambdós es parla directament del seu caràcter. Per la qual cosa, s’hauria de fer un estudi més exhaustiu que analitzés el nombre màxim de casos de violència en l'àmbit del matrimoni a la Mallorca del segle XVII per a veure si coincideixen amb els perfils traçats per altres autors per la resta de territoris peninsulars, o, si bé, pot crear-se'n un de nou. En tot cas, la base de la violència exercida per l'home sobre la dona és la mateixa concepció patriarcal de la societat. Partint de la figura del pater familias i el seu enfortiment a l'Edat Moderna, resulta evident que no només era un fet aillat i la violència cap a les dones anava molt més enllà que la física.

\section{La violència econòmica contra les dones}

Malgrat que els cops podien ser responsabilitat d'un marit amb mala bava, la violència que s'exercia sobre la dona al segle XVII al Regne de Mallorca era diversa. La física és la més evident i la que més crida l'atenció, sobretot pel lligam que encara té amb l'actualitat. Però, com avui dia, també s'ha constatat que les formes d'exercir l'opressió sobre la dona són nombroses.

D'acord amb la documentació consultada, al segle XVII la violència més habitual contra les dones era la que podem denominar econòmica. Les dones a l'edat moderna podien comptar amb el dot, l'escreix i herències per a poder sobreviure després de quedar viudes o soles. No obstant això, les casades tenien la titularitat dels béns parafernals, del dot, de l'escreix i dels guanys ganancials en el cas de la resta de territoris de la Monarquia Hispànica, però eren administrats pels seus marits (fins i tot la pàtria potestat), els quals exercien un control econòmic decisiu sobre la dona i els seus béns (Reguera 2013: 140 i López-Cordón 1998: 110, 129).

En aquest punt rau l'exercici de la violència econòmica que es planteja. En la majoria dels casos analitzats s'observa com hi havia un home proper a la protagonista que se servia del parentesc o d'una relació de proximitat per a quedar-se amb les seves possessions o directament no entregarles-hi quan corresponia, sobretot en els casos de dots.

Altres formes d'exercir la violència per part de l'home era absentar-se sense deixar cap tipus de recurs o manteniment per a la família que deixava. Les causes podien ser l'abandonament per marxar com a soldat, per a emprendre una altra vida, l'empresonament $i$ altres. A més a més, en moltes d'aquestes ocasions els marits estaven endeutats i la reclamació dels deutes afectava l'esposa deixada. 
Victòria Bauçà Nicolau. La violència física i econòmica contra les dones a la Mallorca del segle XVII: una aproximació

Aquest tipus de violència econòmica ha estat objecte d'estudi en diversos territoris de l'antiga Corona d'Aragó (Baixauli 1992 i Fargas 2010), així com també de la resta de la península Ibèrica (López-Cordón 1998 i Reguera 2013). Aquests treballs deixen clara la importància del dot per a la dona casada.

El dot era una quantitat pactada en el moment d'acordar el matrimoni, que la família de la núvia havia de constituir per a ella en concepte de manutenció i cura. Es tractava de l'aliança entre dues famílies i esdevenia una garantia per a les dues parts. A més a més, el dot representava l'autoritat paterna, quan era absent (Fargas 2010: 100-102). Era la manera que tenia la dona de contribuir al manteniment familiar i de quedar emparada davant la possible mort del seu marit.

Hem de tenir present que el dot representava una càrrega per a les famílies i, en moltes ocasions, el treball de les mateixes joves era indispensable per al manteniment familiar. De fet, per necessitat s'arribava a capitalitzar el treball de les joves en forma de dot (Pérez 2001: 74 i López-Cordón 1998: 115). Per la qual cosa podia resultar un problema haver d'entregar diners o a la mateixa filla.

El dot determinava la situació social de la dona, ja que la quantitat variava si es pertanyia a un estament o un altre i si el matrimoni es produïa de manera endogàmica dins del mateix grup socioprofessional. En les ocasions en què el matrimoni suposava mobilitat social ascendent perquè el marit era d'un estament superior, el dot també augmentava (Baixauli 1992: 269 i Fargas 2010: 102). Normalment, era el pare qui feia l'entrega dels diners i, un cop celebrat el matrimoni, l'administració passava a mans del marit. Així i tot, el dot era un element mòbil que no estava circumscrit al moment de l'entrega (Fargas 2010: 102, 105).

A més a més, el promès, en acceptar la dona i el dot, es comprometia a aportar l'escreix que era la meitat o la tercera part de la quantitat dotal, més la meitat de totes les teles, robes i altres draps que es trobarien en l'habitació del matrimoni el dia de la seva mort (Sastre 2017: 38). La propietària del dot i de l'escreix només hi podia accedir després de la mort del marit i, com es pot deduir, no sempre era així.

A Catalunya, el dot era un avanç de la legítima, és a dir, de la part que corresponia a la filla de l'herència, o bé, fins i tot s'utilitzava com a forma de deixar-la fora de la successió (Fargas 2010: 107 i Pérez 2001: 79). Així i tot, no era una fórmula estàtica, sinó que es flexibilitzava segons la conveniència social i familiar. Cal saber que, sobretot a Catalunya, es va deixar poc espai per a la successió femenina, d'aquí l'existència de prelacions de sexe i nupcialitat. De fet, es temia que una dona que ja havia rebut el dot pogués ser declarada hereva universal: una dona amb riquesa acumulada representava un perill (Pérez 2001: 74-78).

En aquest sentit, a Catalunya existeix la figura de l'heretament, que era un conjunt de béns que es donava al matrimoni per evitar que la filla pogués acumular el patrimoni familiar, fet que li donaria una posició preeminent. Per la qual cosa es donava prioritat a l'existència d'un únic hereu, excloent a les dones de l’herència (Pérez 2001: 75-76). 
Victòria Bauçà Nicolau. La violència física i econòmica contra les dones a la Mallorca del segle XVII: una aproximació

El dot no sempre podia entregar-se d'un cop, sobretot si era una quantitat elevada. Per això, es fraccionava i s'entregava en diferents terminis. A més a més, moltes vegades s'optava per la combinació de doblers comptants i l'entrega d'una propietat, la cessió de censals o l'aportació d'un aixovar de la núvia a la casa del seu marit (Sastre 2017: 38-41). Així, el pacte dotal quedava satisfet.

La importància del dot era tal que fins i tot es troben litigis, tant a Catalunya com a Castella, que ocupen dècades i generacions per diferents motius. Un dels més habituals era per la diferència entre la quantitat que s'havia promès i la que s'havia rebut (Fargas 2010: 111-112).

Per una banda, a Mallorca, la primera legislació sobre el dot arribà poc després de la conquesta: en 1251 Jaume I posava a salvaguarda els dots i béns esponsalicis de la dona i els separava del seu marit. És a dir, a Mallorca existia la separació de béns, cosa que diferencia a l'esposa mallorquina de la de resta de territoris -excepte València i Catalunya-, de manera que, juntament amb l'escreix, el dot era l'única possessió que podia tenir (Pérez 2001: 81). Així i tot, el marit seria l'administrador d'aquest patrimoni fins a la seva mort, moment en què la dona podria recuperar-lo. Un segle després Pere IV protegia el dot de la dona contra els creditors del seu marit (Quadrado 2002: 29,70). Per tant, el dot era un element clau per a la dona, tant pel seu estatus com pel seu sosteniment.

Per altra banda, hem de tenir en compte que l'esposa a Mallorca podia ser declarada hereva universal o usufructuària, per la qual cosa també tenia accés als béns familiars un cop hagués finat el seu marit, a banda dels seus propis. Així mateix, passava a tenir noves responsabilitats: l'administració del patrimoni familiar i les tuteles dels fills i de les filles.

Amb l'existència de la separació de béns a Mallorca, el Dret Jurídic mallorquí estipulava que la viuda havia de veure restituït el seu dot i l'escreix un any després de la mort de l'espòs (Sastre 2017: 42). Quan els hereus propietaris eren els fills encara menors i la viuda havia quedat com a hereva usufructuària, s'havia d'esperar per a la restitució del dot fins que els hereus poguessin fer-li entrega.

Aquesta era una pràctica comuna arreu dels territoris, però no només obeïa a la mort del marit. També existien altres causes que motivaven la restitució dotal: la separació o divorci, per exemple (Fargas 2010: 109, 114 i Reguera 2013: 145). Així, retornant al tema anterior, moltes víctimes de maltractaments fugien dels seus agressors amb el dot, cosa que enfurismava encara més als marits que es quedaven sense l'administració d'una quantitat important (Garibeh 2019: 350, Reguera 2013: 145).

Les viudes, com alguns homes, no sempre actuaven en benefici propi sinó de la família, sobretot si es parla dels estaments privilegiats i van esdevenir, en moltes ocasions, copartícips de l'autoritat, tradicionalment masculina (Fargas 2010: 118). Tant el dot com les herències eren un tema clau en l'economia familiar per la qual cosa eren un element central per a afavorir determinats interessos. Per això, es troben exemples d'actuacions i estratègies per a poder continuar el llinatge que tenen a veure amb la conservació o reclamació d'herències o temes relacionats amb els dots (Lorenzo 1989: 122). 
Victòria Bauçà Nicolau. La violència física i econòmica contra les dones a la Mallorca del segle XVII: una aproximació

La família Torrella comptava amb una herència de més de 400 anys, però Alfons Torrella morí intestat deixant una filla de poc més d'un any. Tant l'esposa com la sogra d'Alfons s'havien tornat a casar i davant la por que el patrimoni dels Torrella acabés en mans de les noves famílies d'aquestes dones, un cosí-germà d'Alfons, Joan, reclamà la custòdia, la cura i l'educació de la nina. El que més crida l'atenció és la manera en què van ser presentades la mare i la padrina de la nina en qüestió: interessades només en la nina per l'herència, no tenien cura d'ella. Per tant, el que volia Joan Torrella era allunyar a dues dones externes a la seva família per a poder tenir ell l'herència. Per aconseguir-ho vessà violència verbal contra aquestes dones, deixant-les en mal lloc pel simple fet d'haver-se tornat a casar. Per Presidal decret, la custòdia de la nina passà a mans de Joan Torrella. ${ }^{10}$

Un exemple diferent, però relacionat també en la importància del llinatge i l'economia nobiliaris és el de Margarita Descallar Serralta, viuda de Jordi Abrí Descallar. El difunt havia deixat com a hereu universal al seu fill Guillem, el qual encara era menor d'edat, per la qual cosa s'havia deixat a Margarita com a curadora de l'herència i tutora dels fills. En el testament, Jordi havia deixat unes quantitats en concepte de dot per a la seva filla Beatriu, qui havia de casar amb Jerònim Doms. Ambdós posseïen llinatges nobiliaris per la qual cosa no es tractava d'un matrimoni qualsevol. En veure que no se celebrava, la viuda va veure la necessitat d'augmentar les quantitats del dot de la filla, però aquesta operació només podia ser realitzada per l'hereu de Jordi.

Com a curadora de l'herència del seu fill, Margarita demanà que se li concedís la facultat d'augmentar les quantitats del dot de la seva filla per afavorir el matrimoni. Per això argumentava que, en cas de ser viu, el seu marit faria el mateix. La petició li és concedida. Per tant, podem comprovar com la viuda va ser capaç de seguir lluitant pels interessos familiars utilitzant el seu paper de curadora de l'herència del seu fill menor per a poder garantir la celebració d'un matrimoni molt beneficiós a nivell econòmic i de prestigi per a la família. ${ }^{11}$

Fins i tot, es troben casos en l'estament religiós. En particular, destaca la petició feta per part de les monges del Monestir de Nostra Senyora de la Misericòrdia, que es presentaven com les successores de l'herència d'una de les seves monges, ja difunta. Els pares de Joana Orpí havien deixat a la religiosa una tercera part dels seus béns, la resta era pels seus dos germans, dels quals se'n va perdre la pista. En ella morir, la seva part de l'herència va quedar en mans del monestir i les monges reclamaven també l'herència corresponent als seus germans, ja que aquests es consideraven morts després de no saber d'ells durant 90 anys. ${ }^{12}$

Aquests casos demostren la importància del dot i de les herències per a les famílies i persones dels estaments privilegiats, on les dones hi tenen un protagonisme central i/o secundari, però en cap cas

10 ARM, AA 64, ff. 272v-276v

11 ARM, AA 85, ff. 140v-144r

12 ARM, AA 85, ff. 272r-273v

SCRIPTA, Revista internacional de literatura i cultura medieval i moderna, núm. 16 / desembre 2020 / pp. 343-365 ISSN: 2340-4841 · doi:10.7203/SCRIPTA.16.19234 
Victòria Bauçà Nicolau. La violència física i econòmica contra les dones a la Mallorca del segle XVII: una aproximació

insignificant. No es tractava només d'un assumpte d'estaments mitjans i baixos, sinó que era una constant en l'economia familiar i estamental del segle XVII.

Els interessos sobre uns mateixos béns per part d'hereus propietaris i usufructuaris, que solien ser les viudes, no sempre es resolia amb un pacte amistós. De fet, a l'edat mitjana ja hi ha documentats casos conflictius, tal com demostra Jaume Sastre (2017: 41-43). Un cas habitual que generava disputa era quan la viuda era una dona jove que havia estat la segona esposa del difunt i els hereus eren els fills del primer matrimoni. Aquests hereus solien allargar el pagament de les quantitats que pertocaven a la viuda.

Davant aquests escenaris el rei Sanç I de Mallorca estipulà que la viuda podia romandre a casa del seu marit fins que no se li restituís l'import del dot i l'escreix (Sastre 2017: 42). Un cop cobrades les quantitats corresponents, els immobles i censals que s'havien constituit en dot passaven, però, a mans del germà o del parent més proper, és a dir, deixaven de formar part del dot i ella només podia disposar de la quantitat que se li havia deixat en herència. Així mateix, quan moria ella, el seu dot o bé passava al pare o germà -si seguien vius- o bé als seus hereus i hereves (Fargas 2010: 106).

Les demandes de restitució dotal venien donades per diferents causes i responien al que I. A. Baixauli (1992) qualifica de «la crisi econòmica del matrimoni». Aquests motius eren la mort, l'empobriment, l'abandonament o la bogeria del marit, així com també la mort de la dona. La classificació, per a València, es divideix en quatre tipus de restitucions: causades per la mort del marit, dutes a terme en vida dels cònjuges, causades per la mort de l'esposa i restitucions a les herències de les dotadores que havien passat d'uns a altres i demandes que tenien a veure amb els dots (Baixauli 1992: 265, 270).

En el cas del traspàs del marit qui heretava era la seva descendència, encara que en moltes ocasions van ser les esposes. Aquesta decisió responia a una estratègia, ja que, per davant d'elles, hi havia altres persones de la família (Baixauli 1992: 271). En aquest punt, els encarregats de fer la restitució eren els hereus i les hereves, els tutors, els curadors -que eren els més habituals-, o altres, com els marmessors. Es disposava d'un any per a fer la restitució dotal a la viuda.

Les restitucions que es donaven en vida dels dos implicats responien al no compliment de les obligacions de manteniment familiar normalment causat per l'endeutament, l'empresonament o l'absència del marit. En aquests casos es feia un inventari dels béns del marit per a poder restituir el dot i l'escreix a l'esposa (Baixauli 1992: 274-276). En els casos en què moria primer l'esposa eren els hereus els qui podien sol licitar la restitució dotal al marit si li havia sobreviscut. Si ja havia finat, eren els curadors, els tutors o els hereus mateixos els encarregats de fer la restitució. D'aquesta manera, la restitució dotal es presentava com a la salvació de la crisi econòmica familiar, reforçant el paper econòmic de la dona en el segle XVII (Baixauli 1992: 274-278).

Tanmateix, la dona viuda, en moltes ocasions, veia reduïdes les seves possibilitats econòmiques. Llavors tenia tres opcions: utilitzar els diners que tenia per a constituir-los en dot per a unes segones

SCRIPTA, Revista internacional de literatura i cultura medieval i moderna, núm. 16 / desembre 2020 / pp. 343-365 ISSN: 2340-4841 $\cdot$ doi:10.7203/SCRIPTA.16.19234 
núpcies, passant els seus béns a ser administrats pel nou marit; ingressar en una institució religiosa o convent, i tornar a la casa paterna, ara propietat del seu germà, on poder acabar la seva vida en un segon lloc (Sastre 2017: 42-43).

A banda del dot i l'escreix, el patrimoni d'una dona es completava amb l'herència que podia rebre per part de familiars propers, normalment pares i mares. De fet, dins dels llegats econòmics es poden trobar els mateixos dots de la mare. Per això, es troben disputes entre germans i germanes, oncles i nebodes, $\mathrm{i}$ fins $\mathrm{i}$ tot amb un dels pares vius per a poder accedir a la part de l'herència que corresponia a un o altre. Aquests plets no són exclusius de Mallorca, sinó que el control de les herències i la gestió del patrimoni familiar era font de conflicte en tots els territoris hispànics (Reguera 2013: 150). En general, els homes de la família volien quedar-se amb la part de l'herència que corresponia a la dona. Aquests conflictes no sempre es resolien de manera pacífica i solien allargar-se fins a durar generacions.

Per tant, la situació econòmica de la dona casada a la de la viuda no variava de manera significativa: la dependència d'un home o de terceres persones, com els curadors de les herències (que solien ser homes) era constant. Si, a més a més, es consulta la documentació juridicoadministrativa, es troben molts casos d'abús d'aquesta superioritat amb l'objectiu d'aillar econòmicament a la dona. Aquest és l'altre tipus de violència que es pot comprovar que afectava habitualment les dones del segle XVII a Mallorca.

Una de les fonts on és més evident aquest tipus de violència són els Presidals decrets. Aquest tipus de documentació ens dona molta informació de la situació econòmica de la dona que fa la petició perquè aporta el seu relat, validat moltes vegades amb testimonis i informes econòmics. Malgrat que el gruix del plet pogués trobar-se en la cúria civil de la Reial Audiència, les peticions d'aliments i de pagament dels costos dels litigis es feien a través d'aquest tipus de demandes.

A partir d'aquesta documentació es poden establir tres casuístiques generals per les quals les dones feien reclamacions a nivell econòmic. En primer lloc, s'ha de mencionar la petició de restitució del dot i dels drets dotals i de deposició de l'herència després de quedar-se viudes. ${ }^{13}$ Aquestes dones solien ser de l'estament privilegiat, concretament del grup de ciutadans militars, ${ }^{14}$ i pretenien recuperar la seva part dels diners aportats al matrimoni, és a dir, el dot, que era el que els corresponia per la separació de béns.

A pesar d'haver estat nomenades hereves universals o usufructuàries, les viudes decidiren renunciar als béns del seu marit, moltes vegades per no haver de ser les responsables de la seva administració i les encarregades de litigar amb els creditors. De fet, en un dels casos estudiats s'esmenta que

13 ARM, AA 64, ff. 269r-272v, 343r-344r, 347v-349r

14 Cosa que es pot comprovar en la documentació perquè reben el tractament de magnífiques o honorables, termes associats a aquesta branca de la noblesa mallorquina. (De Montaner, P. i Le-Senne, A. 1979: 234). 
Victòria Bauçà Nicolau. La violència física i econòmica contra les dones a la Mallorca del segle XVII: una aproximació

el motiu de renúncia de l'herència és «veure's molestada i vexada pels creditors del seu marit». ${ }^{15}$ Per això, un cop restituït el seu dot i drets dotals, que ja Pere IV havia protegit dels creditors, sol licitaven el nomenament d'un curador per a l'herència del seu difunt espòs.

En segon lloc, destaquen les peticions que tenen a veure amb el no compliment de les obligacions de manteniment familiar. Malgrat la diversitat de casos, les causes i les conseqüències són molt semblants: la mort o l'absència d'un home provoca la pobresa o manca de recursos per a una sèrie de dones que s'havien d'enfrontar a parents o curadors per a poder mantenir-se.

Així, per exemple, Pereta Sastre havia administrat l'herència del seu marit fins que el seu fill, Guillem Llorenç, va arribar als 20 anys. Aquest, per una banda, havia adquirit el compromís pel testament del seu pare de mantenir a la seva mare. Per altra banda, la seva germana morí sense descendència i ell es quedà amb les seves possessions. Poc després Guillem Llorenç també morí. D'aquesta manera, Pereta es trobava sense ningú que pogués mantenir-la i per això reclamava l'herència de la seva filla morta. Però es topà amb l'oposició de la seva nora, Antonina Coll, qui com a hereva de Guillem Llorenç considerava que li pertanyia. Per això, ambdues dones acabaren en litigis, mentre Pereta sol licitava aliments i el sufragi dels costos del plet. Aquest és un cas excepcional perquè s'enfrontaren dues dones.

L'absència del marit que havia marxat com a soldat feia dos anys també obligà a Caterina Verdera Payeres a reclamar aliments per a poder sustentar-se. El seu espòs havia partit en la companyia de Josep Homar sense deixar cap mena d'instrucció de com havia d'alimentar-se la seva família. La seva esposa només comptava amb el dot, que li era insuficient. Per això, reclamava al curador dels béns del seu marit que li permetés cobrar els arrendaments de les propietats de l'espòs. Finalment per Presidal decret se li taxaren 12 lliures a pagar pel curador dels béns del seu marit per així poder sobreviure. $^{16}$

La figura del curador provocava en nombroses ocasions conflictes quan el responsable dels béns era absent o bé no li interessava implicar-se. Un cas així és el de Joana Verdera: la seva mare havia mort i li havia deixat el seu dot. El seu pare era l'hereu usufructuari i en casar-se en segones núpcies entregà aquesta quantitat a la seva filla perquè considerava injust que acabessin en mans dels descendents del segon matrimoni. La condició que establí fou el nomenament d'un curador i que ella visqués amb la seva tia fins a edat de casar-se. Després d'un temps de viure amb el curador i amb la seva tia, Joana reclamà que es taxessin aliments en concepte del dot heretat de la seva mare, ja que el curador no contemplava el seu manteniment per estar en casa aliena. Al final se li concediren 15 lliures anuals per tots els anys que se li devien i els que vendrien fins poder casar-se. ${ }^{17}$

15 ARM, AA 64, ff. 269r-271r

16 ARM, AA 85, ff. 247r-250r

17 ARM, AA 85, ff. 329v-331r

SCRIPTA, Revista internacional de literatura i cultura medieval i moderna, núm. 16 / desembre 2020 / pp. 343-365 ISSN: 2340-4841 · doi:10.7203/SCRIPTA.16.19234 
Victòria Bauçà Nicolau. La violència física i econòmica contra les dones a la Mallorca del segle XVII: una aproximació

Un cas semblant és el d'Elisabet Soler Seguí, casada en primeres núpcies amb Jerònim Massanet. En aquest morir, es van nomenar dos curadors per a la seva herència, els quals havien de restituir a Elisabet el seu dot i drets dotals que ascendien a una quantitat bastant elevada. En no poder fer-hi front, un dels curadors proposà transferir la possessió La Creu Vella a la suplicant més 40 lliures anuals, de per vida, per a satisfer tals quantitats, a la qual cosa s'oposava l'altre qui acusava la viuda de viure en aquesta possessió com si efectivament ja fos seva. Elisabet demanà la ratificació de la primera solució per veure el seu dot restituit i que se l'eximís del pagament de les despeses derivades d'aquesta possessió. Tot se li va concedir. ${ }^{18}$

Com a últim exemple, destaca el cas de Francina Vanrell Serra, la qual havia estat casada en primeres núpcies amb Nicolau Gomila amb qui havia tingut un fill, que tenia manco de tres anys quan morí el seu pare. Ella es tornà a casar i posà el seu dot i drets dotals en encants. Francina explicava com el seu sogre havia donat quantiosos dots a les seves tres filles, però que no havia donat res al matrimoni del seu fill, és a dir, no havia entregat l'escreix. Després de presentar un informe del patrimoni del seu sogre, Francina demanà que aquest s'encarregués del manteniment del seu fill a partir dels béns que correspondrien al seu pare, és a dir, al seu marit. Juntament amb la presentació de testimonis, aconseguí que Antoni Gomila, el padrí del nin, pagués 12 lliures anuals per al seu net. ${ }^{19}$

Queda clar, llavors, que l'absència del marit era una font de conflictes econòmics per a determinades dones perquè es trobaven sense cap recurs per a mantenir-se ni a elles ni als seus infants. En aquestes disputes, les herències, els dots i l'escreix tenien un paper fonamental, ja que es convertien en la peça clau sobre la qual aconseguir el que demanaven.

Finalment, el tercer grup de demandes fetes per dones a la Reial Audiència és el que més evidencia la violència econòmica exercida per homes, la majoria, parents de la demandant. En tots els casos estudiats és un germà, oncle o pare qui es negava a entregar a la seva parent l'herència o el dot que li corresponien.

Aquests conflictes podien durar anys, fins al punt que trobem filles que segueixen les demandes que havien iniciat les seves mares en contra del seus germans. Aquest és el cas de Francina, Caterina i Magdalena Solivaret Bagur, les quals reclamaven la meitat d'unes cases que suposadament pertanyien a la seva mare, ja morta. La padrina de les demandants tenia tres fills: Miquel, Mateu i Caterina. Al primer deixà l'hort del seu marit, al segon la meitat d'unes cases i l'altra meitat a la filla. Però van establir que si Mateu -el segon- pagava el dot a Caterina, ell podia quedar-se les cases quan tornés a Mallorca. Però el segon germà mai no va tornar ja que va ser captiu a Tunis, on morí sense descendència. L'herència de Mateu va quedar en mans de Miquel, qui no volia entregar a la seva germana la meitat de les cases que corresponien a

18 ARM, AA 85, ff. 215r-218v

19 ARM, AA 85, ff. 200r-203r

SCRIPTA, Revista internacional de literatura i cultura medieval i moderna, núm. 16 / desembre 2020 / pp. 343-365 ISSN: 2340-4841 · doi:10.7203/SCRIPTA.16.19234 
Victòria Bauçà Nicolau. La violència física i econòmica contra les dones a la Mallorca del segle XVII: una aproximació

Mateu. Caterina morí sense aconseguir recuperar el seu dot, per això les filles agafaren el relleu en la reclamació en contra del seu oncle. Finalment aconseguiren la restitució de l'altra meitat de les cases. ${ }^{20}$

L'oncle també és el responsable de la demanda de Sor Antonina Perelló Cantallops, una religiosa del convent de Sant Bartomeu d'Inca. Reclamava el retorn de les 900 lliures que se li havien llegat en contemplació de matrimoni, amb les quals s'havia quedat el seu oncle després de la mort dels seus pares. Davant la seva situació de «pobra religiosa» demanava sumptus litis, ${ }^{21}$ que se li van concedir, així com també 45 lliures anuals a pagar pel seu oncle en concepte d'aliments en funció de les 900 lliures que se li devien. ${ }^{22}$

L'altra figura masculina que surt habitualment en aquest tipus de disputes és la del germà. Des de principis de segle XVII trobem exemples en què el germà es nega a entregar el dot o l'herència a la seva germana. De fet, en els diferents casos, les dones es veuen obligades també a demanar aliments i el pagament dels costos dels litigis que mantenen amb els seus germans a causa de la situació de pobresa en la qual havien acabat com a conseqüència de l'impagament. Per exemple, Francina Oliver Torrandell reclamava l'herència de la seva mare (el dot matern i la legítima) que li pertocava i que havia quedat en mans del seu germà. Davant aquestes peticions, Mateu Torrandell, que era notari, s'havia encarregat «d'enterbolir i fer litigis» en contra de la seva germana perquè aquesta no pogués accedir ni a aquestes quantitats ni a aliments. ${ }^{23}$

Era habitual que aquestes reclamacions s'allargassin per la qual cosa no és estrany que Antoni Salom succeís a la seva mare en la reclamació de l'herència dels seus padrins i del dot matern contra el seu oncle. Aquest estava en situació de pauperisme, per la qual cosa seguia exigint aliments i sumptus litis al virrei. ${ }^{24}$

Un altre cas que crida l'atenció és el de Jerònima Vicens Company, el pare de la qual havia deixat tots els seus béns al seu germà amb la condició que entregués a les seves germanes 400 lliures en contemplació del matrimoni. Trenta anys després d'haver-se casat i ja haver-se quedat viuda, Jerònima encara no havia rebut el seu dot. Per això, demanava que se li paguessin els costos del plet en contra del seu germà per a poder cobrar el dot més els interessos que se'n derivaven de tant de temps d'espera, així com també demanava aliments per la seva condició de pobra. ${ }^{25}$

20 ARM, AA 85, ff. 320v-323v

21 Significa cost del litigi, és a dir, era la manera de demanar que es paguessin les despeses del plet.

22 ARM, AA 85, ff. 14r-15r

23 ARM, AA 64, ff. 211r-212v

24 ARM, AA 64, ff. 278r-280r, 403r-405r

25 ARM, AA 85, ff. 65r-66r

SCRIPTA, Revista internacional de literatura i cultura medieval i moderna, núm. 16 / desembre 2020 / pp. 343-365 ISSN: 2340-4841 · doi:10.7203/SCRIPTA.16.19234 
Victòria Bauçà Nicolau. La violència física i econòmica contra les dones a la Mallorca del segle XVII: una aproximació

Normalment són parents propers els que protagonitzen aquests tipus de conflictes, però el grau de proximitat és relatiu si tenim en compte el cas de Margarita Moll Mulet. Es casà amb Simó Moll de Ciutat feia prop de 5 anys quan va fer la petició. En tot aquest temps, el seu pare, Bartomeu Mulet, no li havia entregat ni diners, ni robes ni béns com a dot, malgrat haver-ho demanat en repetides ocasions. Per a poder reclamar-lo en un litigi contra el seu pare, demanava el pagament dels costos del plet $\mathrm{i}$ que se li taxessin aliments perquè no podia mantenir-se, ja que no comptava amb el dot, que era la principal funció que tenia. Per a sustentar el relat presentà un informe dels béns i patrimoni del seu pare i testimonis. Aconseguí cobrar 24 lliures anuals del seu pare pel deute que aquest havia contret amb la seva pròpia filla. ${ }^{26}$

El primer i el segon grup encaixen en la classificació feta per I.A. Baixauli referent als tipus de restitució dotal: la mort del marit i l'evasiva a mantenir la família, respectivament (1992: 270-277). Fins i tot, alguns exemples del tercer grup podrien encaixar en el quart tipus de restitució del que parla Baixauli: les restitucions a les herències de les dotadores que havien passat d'uns a altres (1992: 270). Per tant, es troben paral lelismes evidents entre el Regne de València i el de Mallorca pel que fa al tipus de violència econòmica exercida contra les dones al segle XVII.

La presentació i explicació de tots aquests casos no resulta en cap cas anecdòtic. La voluntat conscient de deixar sense recursos econòmics a les dones del segle XVII respon a la concepció d'inferioritat que es tenia d'ella en tots els sentits. Per una banda, es reafirmava així la seva minoria d'edat en el terreny econòmic i per altra banda, quedava exclosa socialment perquè molts cops acabaven en la pobresa o en el seu llindar, com es comprova en nombrosos dels exemples presentats. La pobresa per a una dona sola -moltes vegades amb fills/es al seu càrrec- oferia poques opcions decents per a sortir-ne.

Aquesta desigualtat econòmica -provinent del diferent accés a diners, béns i possessions- entre homes i dones reforçava la mateixa estructura patriarcal basada en l'autoritat del pare/marit i l'obediència de la mare/esposa. Si aquests principis es converteixen a l'àmbit econòmic, trobem que les dones quedaven sense possibilitat de viure (i sobreviure) sense la dependència d'un home. Per la qual cosa el seu marge d'actuació també era limitat; les diferents peticions que es registren en la Reial Audiència ho demostren per ser-ne gairebé l'única opció.

L'exercici d'aquest tipus de violència econòmica, plasmada en les tres línies presentades a partir dels Presidals decrets, suposava una forma més de subordinació de la dona a l'home, una reafirmació de la seva inferioritat i la seva manca de llibertat. La dona al segle XVII quedava a mercè de l'home més proper -en el millor dels casos- per a poder mantenir-se. Era una manera més de tenir a la dona fora de l'activitat econòmica i exclosa de la societat.

26 ARM, AA 85, ff. 134v-137v 
Victòria Bauçà Nicolau. La violència física i econòmica contra les dones a la Mallorca del segle

XVII: una aproximació

\section{Conclusions}

Les fonts consultades en aquesta aproximació a la violència que van patir les dones mallorquines al segle XVII ens ha permès comprovar que no era una circumstància aillada. Constatar que apareixen relats de violència en documentació de diferent tipus demostra que era un fet estructural, que formava part de la realitat quotidiana del segle XVII.

En aquest sentit, no només s'ha de fer referència a la violència física, sinó també a totes aquelles formes d'opressió que asseguraven, reforçaven i reafirmaven la subordinació de la dona a l'home, tant en el context familiar com fora d'ell. L'exercici de qualsevol tipus de violència es basava en la concepció de la dona com a ésser inferior a l'home, a qui devia obediència. Per la qual cosa no només podem centrar-nos en els maltractaments físics per a aproximar-nos a la violència contra la dona en els segles de la modernitat.

Queda encara un llarg camí per a traçar unes característiques comunes quant a violència física en contra de les dones en el segle XVII, com pot ser traçar perfils concrets d'agressors o les solucions que es tenien a l'abast. Aquí s'ha presentat un petit esbós del que generalment es produïa. Així i tot, cal seguir fent-nos preguntes: aquesta violència física era tan habitual com es pot pensar? Si estava socialment acceptada, per què trobem denúncies d'aquestes agressions? Si el que es penalitzava era l'abús, qui en fixava els límits? Per tant, queden encara moltes respostes a cercar en les fonts i moltes línies d’investigació a seguir.

Com s'ha dit, existien altres maneres d'assegurar la subordinació i el control de la dona respecte de l'home, fos o no el seu marit. Aquestes diferents formes de tenir-les sotmeses també són violència, d'entre les quals s'ha destacat la vessant econòmica.

L'existència de la separació de béns al Regne de Mallorca marca la diferència amb la resta de territoris peninsulars (excepte Catalunya i València), on els guanys produïts en el matrimoni eren comuns. Aquest sistema deixava a la dona amb accés a uns determinats béns: el dot, l'escreix, els béns parafernals i les herències. Malgrat això, si estava casada l'administració la portava l'home i només podia recuperar-los en quedar viuda. Aquest era un mètode que assegurava el control social i econòmic de l'home sobre la dona i reafirmava la seva autoritat. Per la qual cosa, en tenir aquest tipus de repercussions es pot dir que era un tipus de violència que atorgava un important poder a l'home del qual depenia la dona, fos quin fos el parentesc.

Si a aquest sistema s'afegeixen les diferents estratagemes de les quals van servir-se marits, pares, germans, oncles i curadors d'herències per a no entregar dots i/o herències, descuidar el manteniment de les famílies o no restituir dots a viudes, aquesta violència es fa més greu i evident. En tots els casos, destaca el paral lelisme entre València i Mallorca en els tipus de demandes per a la restitució dotal, per la qual cosa es pot concloure que els vincles entre els regnes de la Corona d'Aragó eren estrets en tots els sentits. 
Victòria Bauçà Nicolau. La violència física i econòmica contra les dones a la Mallorca del segle

XVII: una aproximació

A més a més, la freqüència amb la qual apareixen aquest tipus de demandes fa evident que eren casos habituals, arrelats al mateix ordre patriarcal de la societat. Es pot afirmar que existien diferents tipus de violències que materialitzaven les relacions de poder patriarcal, basades en la diferència sexual, com estableix M. J. de la Pascua (2002: 98).

Cal esmentar que totes les peticions analitzades van ser fetes tant per dones del comú com de l'estament privilegiat, les quals reclamaven dots i herències del mateix mode. Per la qual cosa no es tracta d'un fenomen propi d'un estament en concret. El punt comú d'aquestes reclamacions era que totes eren dones que patien aquest tipus de violència. Havien quedat sense la llibertat de disposar dels seus propis diners i béns i, automàticament, dependents de terceres persones, que no eren sinó homes.

Malgrat patir aquestes violències i opressions es constata un paper reivindicatiu de les dones, ja que en els diferents casos presentats totes fan servir els recursos al seu abast-inclosos els jurídics- per a poder trobar la millor solució a la seva situació. Aquesta actitud rompia amb la imatge de dona incapaç de resoldre els seus problemes i que ja va ser apuntada per T. A. Mantecón (2009: 228).

Així, les mallorquines van saber trobar la manera i la solució per a salvaguardar la seva integritat, els seus drets i les seves possessions. En el cas de la violència física, a través de la fugida de la casa i la petició de divorci, i en el cas de la violència econòmica, amb la presentació de plets contra els homes que impedien l'accés als seus béns.

Per tant, les dones mallorquines es van mostrar capaces de combatre activament aquestes situacions que menyspreaven la seva condició de dones pel simple fet de ser-ho per la mentalitat que governava el segle. D'aquesta manera, es van enfrontar als homes i van saber acudir a la justícia per a poder aconseguir allò que els corresponia. 
Victòria Bauçà Nicolau. La violència física i econòmica contra les dones a la Mallorca del segle XVII: una aproximació

\section{Bibliografia}

Aragón, A. (2011) «Familia, mujer y conflictividad en Guipúzcoa durante la Edad Moderna», Boletín de la R.S.B.A.P., LXVII, 1-2, pp. 43-86.

Baixauli, I.A. (1992) «La dona davant la crisi económica del matrimoni: devolucions de dots en la València del segle XVII», Estudis: revista de historia moderna, 18, pp. 261-278.

Bauçà, V. (2020) «Una nueva mirada sobre los 'Presidals decrets': fuente para el estudio de biografías de mujeres» dins Massanet, R./ Garí, M.G./ García, F.J. De la Reina al carpintero. Biografías de época moderna, entre la bistoria y la literatura, Madrid/Porto: Sindéresis, pp. 257-266.

De la Pascua, M.J. (2002) «Violencia y familia en la España del Antiguo Régimen», Estudis: Revista de bistoria moderna, 28, pp. 77-102.

De Montaner, P./ Le-Senne, A. (1979) «Nobleza, comercio y corso en la Mallorca moderna: los 'negocis per mar' de los Sureda», Mayurqa: revista del Departament de ciències històriques i teoria de les arts, 79-1, pp. 233-243.

Diccionari Català-Valencià-Balear. https://dcvb.iec.cat/ [Recuperat 09/09/2020]

Espín, R.M. (2016) «Los pleitos de divorcio en Castilla durante la Edad Moderna», Studia historica. Historia moderna, 38, 2, pp. 167-200.

Fargas, M. (2010) «Hacia la autoridad contestada: conflictividad por la dote y familia en Barcelona (ss. XVI-XVII), Investigaciones históricas, 30, pp. 99-118.

Garibeh, A. (2019) «La mujer oprimida, la mujer maltratada. Una aproximación a la violencia contra la mujer a través de las escrituras notariales de perdón» dins Fernández Valle, M. Á./ López Calderón, C./ Rodríguez Moya, I. (eds.) Discursos e imágenes del barroco iberoamericano, vol. 8, Santiago de Compostela y Sevilla, Andavira Editora S. L., E. R.A.Arte, Creación y Patrimonio Iberoamericanos en Redes/ Universidad Pablo de Olavide, pp. 345-358.

Gil, A. (2008) Historia de la violencia contra las mujeres, Madrid, Ediciones Cátedra.

Juan, J. (1994) «La instauració de la Reial Audiència al Regne de Mallorca», Pedralbes, revista d’història moderna, 14, pp. 61-79.

López-Cordón, M.V. (1998) «Familia, sexo y genero en la España moderna», Studia historica. Historia moderna, 18, pp. 105-134.

Lorenzo, P.L. (1989) «Los malos tratos a las mujeres en Castilla en el siglo XVII», Cuaderno de investigaciones históricas Brocar, 15, pp. 119-136.

Mantecón, T. A. (1997) Conflictividady disciplinamiento social en Cantabria en el Antiguo Régimen, Santander, Servicio de Publicaciones. Universidad de Cantabria.

Mantecón, T. A. (2009) «Hogares infernales: una visión retrospectiva sobre la violencia doméstica en el mundo moderno» dins Lorenzo, F.J. (ed.) La familia en la historia, Salamanca, Ediciones Universidad de Salamanca, pp. 187-230. 
Victòria Bauçà Nicolau. La violència física i econòmica contra les dones a la Mallorca del segle XVII: una aproximació

Mantecón, T. A. (2013) «Impactos de la violencia doméstica en sociedades tradicionales: La muerte de Antonia Isabel Sánchez, quince años después», Memoria y civilización, 16, pp. 83-115.

Morte, A. (2012) «Que si les oían reñir o maltratar el marido a la mujer la socorriesen: familia, vecindad y violencia contra la mujer en la Edad Moderna», Revista de historia moderna, 30, pp. 211-227.

Ortega, M. (1997) «El período barroco (1565-1700) dins Garrido, E. (ed.) Historia de las mujeres en España, Madrid, Editorial Síntesis, pp. 253-344.

Ortega, M. (2006) «Violencia familiar en el pueblo de Madrid durante el siglo XVIII», Cuadernos de Historia moderna, 31, 7-37.

Pérez, I. (2001) «Pubilas y cabaleras en la Cataluña moderna», Obradoiro de historia moderna, 10, pp. 73-88.

Petro del Barrio, A. (2006) La legitimación de la violencia en la comèdia española del siglo XVII, Salamanca, Ediciones Universidad de Salamanca.

Planas, A. (1999) «Las penas en el derecho histórico de Mallorca», Bolletí de la Societat Arqueològica Lul tiana, 55, pp. 85-118.

Planas, A. (2000) «Los delitos contra el matrimonio y la moral sexual en el Derecho histórico de Mallorca», Bolletí de la Societat Arqueològica Lul liana, 56, pp. 45-64.

Planas, A. (2010) La Real Audiencia de Mallorca en la época de los Austrias (1571-1715), Barcelona, Universitat Pompeu Fabra.

Quadrado, J.M. (2002 [1a edición 1894]) Privilegios y Franquicias de Mallorca, Palma, Conselleria d'Educació i Cultura del Govern de les Illes Balears.

Reguera, I. (2013) «Malos tratos y violencia conyugal en la sociedad vasca de la Edad Moderna», Memoria y civilización, 16, pp. 137-174.

Sastre, J. (2017) La dona medieval a la Ciutat de Mallorca (segles XIII-XV), Palma, Lleonard Muntaner editor.

\section{Fonts}

ARM AA 64

ARM AA 85
ARM AA 1023

ARM AA 935/7 3/59 